\title{
LETTER
}

\section{Underpowered trials in critical care medicine: how to deal with them?}

\author{
Bob Roozenbeek ${ }^{1,2 *}$, Hester F Lingsma², Ewout W Steyerberg ${ }^{2}$ and Andrew IR Maas'; \\ on behalf of the IMPACT Study Group \\ See related research by Aberegg et al., http://ccforum.com/content/14/2/R77
}

In their recently published article, Dr Aberegg and colleagues described interesting results of a literature search for randomized controlled trials comparing mortality of therapies for critically ill adults in five high impact journals over a 10 year period [1]. The authors show that the predicted delta (the effect size of a therapy compared to control) used for power calculations was substantially larger than the observed delta in the majority of the included studies. They conclude that this finding, referred to as 'delta inflation, led to underpowered trials in the field of critical care medicine.

We agree that treatment effects are small in this field of medicine and that many critical care trials have been underpowered. This problem is particularly relevant to the field of neurocritical care after traumatic brain injury [2]. The IMPACT (International Mission on Prognosis and Clinical Trial Design in Traumatic Brain Injury) Study Group extensively investigated possible causes and solutions and recently reported recommendations for improving the design and analysis of future clinical trials in traumatic brain injury to increase statistical power [3]. These include the use of relatively broad enrolment criteria instead of strict patient selection [4], covariate adjustment for baseline patient characteristics [5], and ordinal rather than dichotomous outcome analysis [6]. In our opinion these recommendations are also applicable to other fields of critical care research characterized by heterogeneous patient populations. We submit that adopting these recommendations in future trials will increase the chance of detecting small but clinically relevant treatment effects in critical care medicine.

\section{Competing interests}

All authors are members of the IMPACT Study Group. The work of the IMPACT Study Group is funded by a grant of the US National Institutes of Health (NS-042691).

\section{Author details}

'Department of Neurosurgery, Antwerp University Hospital, Wilrijkstraat 10, 2650 Edegem, Belgium. 2Department of Public Health, Erasmus MC, PO Box 2040, 3000 CA, Rotterdam

Published: 8 June 2010

\section{References}

1. Aberegg SK, Richards DR, O'Brien JM: Delta inflation: a bias in the design of randomized controlled trials in critical care medicine. Crit Care 2010, 14:R77.

2. Maas Al, Roozenbeek B, Manley GT: Clinical trials in traumatic brain injury: past experience and current developments. Neurotherapeutics 2010, 7:115-126.

3. Maas Al, Steyerberg EW, Marmarou A, McHugh GS, Lingsma HF, Butcher I, Lu J, Weir J, Roozenbeek B, Murray GD: IMPACT recommendations for improving the design and analysis of clinical trials in moderate to severe traumatic brain injury. Neurotherapeutics 2010, 7:127-134.

4. Roozenbeek B, Maas Al, Lingsma HF, Butcher I, Lu J, Marmarou A, McHugh GS, Weir J, Murray GD, Steyerberg EW: Baseline characteristics and statistical power in randomized controlled trials: selection, prognostic targeting, or covariate adjustment? Crit Care Med 2009, 37:2683-2690.

5. Hernández AV, Steyerberg EW, Butcher I, Mushkudiani N, Taylor GS, Murray GD, Marmarou A, Choi SC, Lu J, Habbema JD, Maas Al: Adjustment for strong predictors of outcome in traumatic brain injury trials: $25 \%$ reduction in sample size requirements in the IMPACT study. J Neurotrauma 2006, 23:1295-1303.

6. McHugh GS, Butcher I, Steyerberg EW, Marmarou A, Lu J, Lingsma HF, Weir J, Maas Al, Murray GD: A simulation study evaluating approaches to the analysis of ordinal outcome data in randomized controlled trials in traumatic brain injury: results from the IMPACT Project. Clin Trials 2010, 7:44-57.

doi:10.1186/cc9021

Cite this article as: Roozenbeek B, et al:: Underpowered trials in critical care medicine: how to deal with it?. Critical Care 2010, 14:423. 